\title{
AMERIKAANSCHE SPDORWEGEN.
}

In het jaar 1868 eindigde de heer W. v. O. B. zijne beschou* wingen over: "Amerikaansche fondsen als geldbelegging" met deze woorden :

"Alle menschelijke berekeningen zijn feilbaar, en in de toekomst „kan niemand met zekerheid zien; doch wij vermeenen te hebben "aangetoond, dat de Amerikaansche waarden meer zekerbeid be"zitten, dan meest alle Europeesche; wil men van deze wenken "gebruik maken, helzij door verwisseling, hetzij door aankoop, "men vergeijike daartoe slechts de prijzen van de Europeesche "en Amerikansehe fondsen met elkander en bepale zich dan tot "de 5 en 6 pCt. obligatiën der Unie, en andere fondsen der "Noordelijke Staten, Aandeelen of 6 of 7 pCt. Oblig. Illinois"Spoorweg, en Oblig. St. Paul en Pacific Spoorweg; men vindt op "dat gebied overvloedige keuze."

Toen wij onlangs deze woorden herlazen, brachten wij ze van toepassing op de voorvallen van de laatste maandeu, die juist het tegenovergestelde ons deden aanschouwen van hetgeen de kundige schrijver vijf jaren geleden meende te mogen voorspellen. In plaats dat de Amerikaansche waarden meer zekerheid bezitien dan meest alle Europeesche, zijn zij voor een groot gedeelte in de publieke meening reeds afgedaald tot den rang van scheurpapier, althans wanneer men de prijscouranten der effecten als waardemeter aanneemt. Toch moet des schrijvers vertrouwen in de deugdelijkheid en rentabiliteit der Amerikanache Spoorwegwaarden bijzonder groot zijn geweest, wanneer hij haar als solide geldbelegging aanprijst, niettegenstande de treurige ervaring, die reeds toen van twee der meest bekende was opgedaan. Immers in 1857 werd de betaling van den October-coupon van de 7 pCt. Illinois Construction Bonds ten gevolge eener geldkrisis eenige weken uitgesteld, terwijl in December 1864, de toen vervallen coupon vau den 7 pCt. St. Paul en Pacific Spoorweg door buitengewone daling Econ, 1873. 
van alle Amerikanusche waarlen eerst eenige maanden later werd betaald. Wij schrijven nu 1873 en moeten weder het sehouwspel beleven, dat eene Amerikaansche Spoorweg-Maatschappij niet in staat is hare finantiële rerplichtingen na te komen. Verscheidene waarden hebben ter beurze eene gevoelige daling ondergann, en haar wankelend crediet heeft dit effect gesorteerd, dat de solide (en die zijn er inderdaad) lijden onder den schadelijken invloed van het toenemend wantrouwen in hare slechte zusters.

Waar dergelijke feiten, die meer en meer getuigenis geven van eenen ziekelijken toestand in onze handelswereld, zich in eu om ons vertoonen, daar aarzelen wij niet de pen op te nemen en te waarschuwen tegen het rolgen van een weg, die naar onze ernstige overtuiging menigeen ten gronde zal voeren. Oefenen dan de hooge dividenden en enorme winsten die in prospectussen en staten der goê gemeente worden voorgespiegeld, op baar dergelijke aantrekkingskracht uit, dat overwegingen van anderen aard ten eenenmale worden buitengesloten? Zijn de Nederlandsche guldens en rijksdaalders goed genoeg, om de kassen te vullen van Amerikaansche generaals, die voor Amerikaansche spoorwegen geen of althans geen voldoend Amerikaansch kapitaal kunnen beikomen en zich wel willen belasten met het beheeren en beleggen onzer gelden?

Wij worden bitter, maar niet zonder reden, want wij hebben in den Nederlander van den tegenwoordigen tijd meer en meer eene deugd zien ontbreken, die aan zijne voorvaderen in hooge mate eigen was. Wij bedoelen de oud-Hollandsche voorzichtigheid. De dobbelwoede en speelzucht hebben ons zó aangestoken en beheerschen ons dermate, dat wij oog en oor verliezen voor alles wat in onze werkelijke belangen ingrijpt en met onze nationale welraart in nauw verband staat. Het deed ons daarom goed, toen wij in een der boofdorganen onzer pers, namelijk het Vaderland, in de nummers van Zaturdag en Masndag 3 en 5 Mei II., een artikel zagen opgenomen, dat onder den titel van: "Een wondeplek in ouze Maatschappij" den toestand in bet juiste licht beschouwt en over de veege teekenen des tijds een diep af keurend oordeel uitspreekt. Wij onderschrijven de strekking van dat betoog ten volle en brengen bulde zoowel aan het talent en de kennis van personen en toestanden, die de schrijver in zijn uitmuntend gestyleerd artikel heeft aan den dag gelegd, als aan den vorm waarin hij aan zijne lezers zijue denkbeelden lreeft ontrouwd. Wanneer wij éénen wensch mogen uiten, dan is het dese, dat ${ }_{n}$ het Vader- 
land" zal mogen voortgaan met het Nederlandsch publiek te wijzen op dergelijke wonde plekken, die dikwijls zoo moeielijk, wellicht nimmer weêr genezen en aan zoo menig onzer voor altijd den genadeslag hebben toegebracht.

Wij hebben over het algemeen weerzin tegen Amerikaansche spoorwegwaarden, maar staan in ons ongunstig oordeel niet alleen. Van waar anders het verschijnsel, dat, niettegenstaande de schitterendste aanbiedingen, menige commissionnairsfirma te Amsterdam steeds de verzoeking beeft weêrstaan en hooghartig voor de eer heeft bedankt om haren naam en haar crediet te verbinden aan het importeren van dergelijk papier? Sleehts weinige weken geleden toch kon men op eene vergadering van belanghebbenden en belangstellenden in de Amerikaansche spoorwegfondsen, belegd door het Administratie-kantoor onder directie der heeren Wertheim en Gompertz, Westendorp en Co. en F. W. Oewel, ten duidelijkste bespeuren dat die waarden geenszins op een onverdeeld vertrouwen konden aanspraak maken, en dat aan hare deugdelijkbeid vrij algemeen werd getwijfeld. (*) $\mathrm{Wij}$ betreuren het dan ook, dat die vergadering niet het minste practisch resultaat heeft opgeleverd, en dat men zich bij algemeene beschouwingen heeft beperkt, daar waar voorlichting en bespreking van elk der waarden afzonderlijk zoozeer gewenscht en noodig was. De Memorie van Toelichting, waarom de vergadering zal worden gehouden, nl.: „ten einde gemeenschappelijk de middelen te bespreken, welke de "Nederlandsche beurzen kunnen aanwenden om op afdoende wijze "de depreciatie tegen te gaan in Amerikaansche spoorwegwaarden, "voor zooverre die kunstrnatig in het leven wordt geroepen en "alleen berust op gemis aan kennis of toelichting bij de houders," geeft ons den indruk, dat men bier eene kunstmatige rijzing heeft willen tot stand breugen. Zulks achten wij ten eenenmale verkeerd, en wij zien niet de minste reden, waarom het publiek de verklaringen, die nu worden verstrekt, voor goede munt zoude moeten aaunemen, nadat gebleken is, dat de beloften van voorheen zoo slecht vervuld zïn geworden.

Aan de onvermoeide en ijverige zorgen van den kundigen Am.

(*) Daartoe leze men slechts de roude en eerlijke verklaring der heeren ten Have en van Essen, in een ingezondeu stik van het Algemeen Haudelsblad van 2 Julij 11. behelzende de redenen, waarom zij geen deel wenschen uit te maken van eene commissie van onderznek van een voorstel, aaugeboden door het Administratie. kautour van Amerikansehe spoorwegfoudsen. 
sterda inschen Secretaris der Kamer van Koophandel en Fabrieken, den heer Mr. N. J. den Tex, hebben wij het te danken dat in de laatste maanden een weinig meer licht is opgegaan over de hier te lande in omloop zijnde Amerikaansche waarden. De schrijver heeft naar onze bescheiden meening een verdienstelijk werk verricht en mag aanspraak maken op den dank van alle belanghebbenden en belangstellenden, dat hij in zijn geschrift : "Amerikaansche spoorwegen op de Amsterdamsche Beurs" op eene even duidelijke als beknopte wijze omtrent elk dier waarden de meest naauwkeurige inlichtingen heeft verstrekt en daarbij niet verzwegen heeft de rampen, die door verseheidene maatschappijen zijn aangericht of de verliezen die door haar zijn geleden, terwijl hij tevens de namen der firma's, die een of ander fonds aan de markt brachten, heeft vermeld. Aan dat geschrift, dat wij gaarne in ieders handen wenschen te zien, ontleenen wij de volgende bijzonderheden :

De Boston-Hartford-Erie-spoorweg is gefailleerd en bare aandeelen werden in het laatst van April en in Mei van dit jaar op dezelfde wijze verhandeld als voor vijftig jaren de beruchte Poyezen;

de Erie-spoorweg, ofsehoon behoorende tot de best geexploiteerde van geheel Amerika, is jaren lang blootgesteld geweest an do schandelijkste practijken en zwendelarijen van bare Directie;

de Atlantic en Great Western is nog niet eens in staat de rente van hare eerste hypotheek te betalen, terwijl processen en pogingen tot schikking onophoudelijk moesten plaats hebben;

de Port-Huron en Chicago heeft hare coupon ran Mei 1872 niet betaald en sloot op 31 December 1872 met een nadeelig saldo van Dr. 111.332;

de coustructie van de St. Vincent Brainard Extensions, een der zijtakken van den Paul en Pacific, 1ste division, moest in het najaar van 1872 worden gestaakt wegens gebrek aan de noodige fondsen;

de Chicago-South-Western kon in November 1872 haar coupon voor de hoofdlijn en in December van datzelfde jaar baar coupon op de Atchison-Branch, eene harer zijlijnen, niet betalen;

de Rockford-Rock-Island en St. Louis-Maatschappij is een toonbeeld van wanbeheer en van uitplundering der obligatie-houders; de des-Moines-Valley voldoet sedert October 1871 geregeld geen van hare coupons meer, terwijl allerlei voorstellen tot reconstructie der Maatschappï hebben schipbreuk geleden;

de North-Missouri werd den 26 Augustus 1871 in publieko 
veiling verkocht door de houders der 2 e hypotheek voor Ds. 2.000000 contant en tegen overname der $1_{B}$ hypotheek aan de Kansas-City en Northern spoorweg; de nieuwe maatschappij werd echter reeds den 13 September 1872 in publieke veiling gerechtelijk verkocht voor Ds. 45000 aan den president der maatschappij;

de Californië-Pacific, Elisabeth-town en Paducahn, Oregon en Californië, Alabama en Chattanooga weigeren hardnekkig in. lichtingen te geven omtrent hare exploitatie-rekening;

de $8 \%$ Florida stelde de betaling van den Julij-coupon van 1872 uit tengevolge van eene aanklacht tegen haren Gouverneur wegens zijne handelingen in zake dien spoorweg en tengevolge van processen over verdere vorderingen.

En hoo komen nu de meeste Amerikaansche spoorwegen tot stand? De heer H. J. Oyens zegt het ons in zijn geschrift over : "Amerikaansche Spoorwegwaarden voor Nederlandsche kapitalisten." (") Wij lezen aldaar op pag. 9 het volgende:

"In den regel worden Westersche spoorwegen geconstitueerd "met een zeer klein share-kapitaal, dat gewoonlijk gevormd wordt " door de oprichters en de aannemers, die dan de concessie en „, een klein gedeelte van het werk in betaling geven. Eenige shares "worden verder genomen door de Counties en Townships, waar"door en waarlangs de geprojecteerde weg zal loopen, en deze "laatsten zijn vaak de eenige aandeelhouders die werkelijk hunne "aandeelen in geld betalen. Het verder benoodigde geld voor den "aanleg moet geleverd worden door de nemers van obligatiën, "die al spoedig na de oprichting der Maatschappij, tegen eene goede "provisie, door tusschenkomst van het een of ander bankiershuis, "aangeboden worden. Gewoonlijk is echter in Amerika niet ge"makkelijk plaatsiug voor deze waarden te vinden, daar de zeker"heid als roorzichtige geldbelegging niet groot genoeg is, terwijl "speculanten en handelaren, die in den regel in zaken minstens "10 pCt. maken, hunne gelden niet in zulke effecten beleggen. "Dan tracht men in Europa het débouché te viuden, dat in het "land zelf niet gevonden kan worden. Een of ander bankiershuis " in Europa wordt opgezocht, en door hooge provisiën en schoone "voorstellingen verlokt, wordt er allicht een gevonden, dat de „nieuwe zaak aan de markt brengt. Veelal zijn de Amerikaansche "huizen, die zich met deze soort van zaken afgeven, jonge huizen, "eersi sints den oorlog bekend en daardoor vaak ook niet het

(*) Amsterdam, H. de Hoogh en Co. 1870. 
„meest gencerditeerd Wat de Europeesche baukiershuizen aan"gaat, bij dezen is in den laatsten tijd wet het aanbieden dezer "obligatien een gebruik ontstaan, dat voor deze soort van zaken "niet pleit. Als waren zij zelven overtuigd, dat hunne gunstige "opinie omtrent de door hen aangeboden obligatiën op losse "gronden steunt, zijn zij, en met reden, huiverig hunnen nam "te leenen voor de aankondiging, en laten daarom de annonces "en prospectussen teekenen door commissionnairs, die gew oonlijk "van hen af hankelijk, en voor wie de winsten, door zulk een naam "leenen to behalen, niet onverschillig zijn. De zaak wordt voorts "dikwijls ondersteund door réclames in den vorm van gunstige "berichten omtrent de nieuwe spoorweglijn (vaak overgenomen "uit enkele Amerikaansche finantiële bladen, waarvan het slechts "al te bekend is dat zij onder den invloed van Amerikannsche "financiers staan); door telogrammen uit het buitenland, waarin "hoog wordt opgegeren van de deelneming in de leening, door "kunstmatig bewerkte booge koersen, door schoone advertentien "in den vorm van raadgevingen, en dergelijke handelingen meer."

Die woorden zijn waar en doen de persoon, die ze uitte en-ter nederschreef, eer aan. Eenigen tijd geleden werd ons namelijk uit New-York toegezonden een exemplaar van bet: "Bulletin de New-York. Journal hebdomadaire. Finances. Commerce. Chemins de fer. Immigrations. Mines." Wij doorliepen dat blad, dat, naar onze bescheidene meening inderdaad niet zonder talent wordt geredigeerd, en al lezende, viel ons oog op het: „Tableau des cours à la bourse de New-York." Wat was natuurlijker, dan dat wij de prijscourant van onze Amsterdamsche effectenbeurs ter hand namen en eens gingen vergelijken, welke Noord- en Zuid-Amerikaansche Spoorwegfondsen zooal op beide beurzen worden verhandeld. Wij geraakten toen tot de wetenschap, dat op de Amerikaansche beurs geheel andere waarden werden vernegotiëerd als op de Amsterdamsche. Zoo vond men op de eerste: New-York-Central, Albany en Susquebanna, Munro en Toledo, Bellevue en St. Ills, Alton en Terre-Haute, St. Louis en Iron, Toledo en Wabash, Hannibal en Naples, New-YerseyCentral, New-York en New-Haven, en nog zoovele anderen, die, voor zooverre ons bekend is, en de ons verstrekte inlichtingen juist zijn, nimmer hier ter markt zijn gebracht. Daarentegen troffen wij op de Amsterdamsche prijscourant namen aan, waarvan wij op die van New-York te vergeefs de plaats zochten, b. v. Californië-Oregon, St. Joaquin-Valley, Marietta Pittsburg, Den- 
ver-Pacific, Gilaau-Springfield, Denver-Rio-Grande, Denver-Boulder, enz.

Ofschoon niet gerust, willen wij niet zoo wantrouwend zijn en reeds dadelijk het vermoeden opperen, dat er wel eens een dier Spoorwegwaarden met een' prachtig klinkenden naam kon zijn, die alleen in de verbeelding der schuldeischers bestaat. Maar eene aandachtige overweging der bovenaangehaalde woorden van den heer Ojjens, waar bij zegt dat in Amerika zelf voor de platsing van spoorwegwaarden in de meeste gevallen moeijelijk een bankiershuis is te vinden, dat zich daarmede wil belasten, en dat men zich dus wel moet wenden naar Europa waar licht bet een of ander buis zich tegen het genot eener behoorlijke provisie de moeite van het aan den man brengen der leening en van de emissie der stukken wil getroosten, geeft ons aanleiding tot de vrees, dat de slimme Yankee de beste waarden voor zijn eigen land heeft bewaard en zich niet ontziet, om de insoliede of twijfelachtige der Nederlanders in den maag te duwen. Is die vrees inderdaad gegrond, dan handelen wij onverantwoordelijk. Want, terwijl wij aan onze eigene spoorwegen, die met buitenlandsch kapitaal moesten worden opgericht, den zoo boog noodig geldelijken stenn onthouden, gaan wij de kassen van vreende, ons ten eenenmale onbekende en onverschillige spoorweg-maatschappijen stijven en zien met de meeste lijdzaambeid het geld het land verlaten. Eenige maanden geleden roerden wij betzelfde onderwerp aan in ons artikel: "Beschouwingen over de Amsterdamsche Beurs," $\left({ }^{*}\right)$ naar aanleiding van een destijds tusschen twee Amsterdamsche commissionairs firma's aanhangig rechtsgeding over levering van Amerikaansche Spoorweg-obligatiën. Hetgeen wij toen in het midden brachten heeft ook nu ten volle zijne beteekenis en kracht behouden; want de processen, die sints dien tijd zijn gevolgd, waren vele. Wij wenschen echter niet in herbalingen te vervallen, maar alleen de hoop uit te spreken, dat de tijd spoedig moge aanbreken dat wij met recht van waarheid mogen getuigen, dat onze handel en nijverheid moreel en materieel worden gesteund door uitsluitend Nederlandsch kapitaal.

Nog iets. Ieder, die zijn liapitaal aan de eene of andere maatschappij verstrekt en daardoor te kennen geeft in haar een zeker vertrouwen te stellen, zal toch, even als elk schuldeischer, wel in de eerste plaats behoeven het recht van contrôle, ten einde

(*) Zie Economist 1872, 2e deel, bl. 1048. 
zich ran den gang en stand ran zaken olk oogenblik persoonlijk te kunnen overtuigen. Hoe zal hij nu ooit een behoorlijk gemotiveerd vonnis kunnen vellen, wanneer hem dat toezicht foitelijk onmogelijk is door den enormen afstand, die hem van zijnen schuldenaar scheidt? Of zal hij maar onvoorwaardelijk geloof moeten hechten aan de schitlerende staten, wemelende van ontvang. sten en hoog opgevende van behalde winsten, die de Directie van den een of anderen spoorweg hem gelieft voor te leggen, al bestaat er ook niet de minste reden om aan hare waarheidsliefde te twijfelen?

Ons wantrouwen in de Amerikaansche spoorwegfondsen schijnt ons te meer gegrond, wanneer wij zien dat in Amerika zelf zich ongunstige kenteekenen vertoonen. Van tijd tot tijd toch gaan in de Unie stemmen op tegen de roekelooze, ja schaamtelooze wijze, waarop sommige Directeuren van Spoorweg-Maatschappijen omspringen met de aan hunne zorg toevertrouwde kapitalen. Het beruchte proces tegen Jay Gould, den Directeur van den Erie. Spoorweg, levert daarian een treurig bewijs.

Het is eene waarheid, en wel eene waarheid gegrond op feiten, welke zich dagelijks in onze matschappij voordoen, dat de bloei en de welvaart eener onderneming voor het grootste gedeelte, dikwijls uitsluiteud, afhangen van de personen die aan haar hoofd zijn geplaatst. De kunde, jjrer, waakzaambeid, rechtschapenheid, in één woord alle uitnemende gaven van geest en hart, vereenigd in den persoon van het hoofd eener aaak, boezemen aan bet publiek vertrouwen in en schenken aan de zaak reeds bij voorbaat daardoor een crediet, dat zij geheel met den persoon geidentificeerd wordt. Het ligt yoor de hand, dat bij Amerikaansche fondsen een dergelijk onderzoek steeds zeer moeielijk zal zijn en dat eene geldbelegging daarin dus aan zeer vele bezwaren onderhevig blijft. Vóór alles lette men er echter onzes inziens zovveel mogelijk op, of het bestuur der onderneming aan goede handen is toevertrouwd en zij men niet te lichtvaardig met het schenken van een vertrouwen, dat later wel eens kon blijken geheel misplaats te zijn geweest. Eerst daarna onderzoeke men of de zaak, an welke men voornemens is zijne gelden te verstrekken, rendabel is, hoe groot de kosten van aanleg zijn, welke verhouding er bestaat tusschen het aandeelen- en obligatiën-kapitaal, hoeveel de bruto- en nettoontvangsten per mijl bedragen, en welke verhouding er bestaat tusschen de exploitatie-kosten en het bruto bedrag der ontvangsten. Men geve daarbij de voorkeur aan voltooide lijnen, 
over welke men kan oordeelen, boven die welke nog alleen op papier bestaan.

Aan deze wenken, ons door den Heer Oijens in zijne flink geschreven brochure versehaft, zouden wij slechts ééne wenschen toe te roegen, en wel als algemeene regel: "in dubio abstine." Is eene spoorwegleening van dien aard, dat de zaak weinig of geen finantieël succes belooft in de toekomst, of zijn de geldelijke voordeelen, die voorgespiegeld worden, eenigzins vaag of precair, dan zouden wij wel dezen raad willen geven: misgunt de leening niet aan hen, die u uitnoodigen, om haar te helpen volteekenen. Zij hebben de leening eenmaal gekocht; welnu, laat ze haar behouden! Was zij goed, dan is voor uw kapitaal toch wel eene andere, misschien nog nuttiger plaatsing te vinden. In ons eigen vaderland valt zooveel te vormen en te verbeteren, dat wij ons waarlijk niet met de belangen van het verre Westen behoeven bezig to houden. Blijkt het daarentegen, dat de zaak op vicieuse grondslagen is gebaseerd, welnu! des te betér voor $u$, des te slechter voor hen. Men kan dan op de emittenten met het volste recbt toepassen bet: „habent quod sibi imputent."

De geldbelegging in Amerikaansche spoorwegfondsen vindt ook hier te lande hare verdedigers, niet alleen in de finantiële pers, maar ook in sommige handelskringen. Men heeft baar zelfs trachten te verdedigen op grond dat eene plaatsing van kapitalen in binnenlandsebe handel en nijverheid dikwijls zoo weinig aan de verwachting beantwoordt. Wij zijn onpartijdig genoeg om te erkennen, dat hier te lande bij de oprichting van maatschappijen somtijds meer op het persoonlijk belang van individuen wordt gelet dan op het gewicht en de levensvatbaarheid der zaak zelve. Maar door een dergelijk argument is allerminst een pleidooi voor de vreemde geldbelegging gerechtvaardigd, die dezelfde en misschien nog meerdere risico's kan opleveren. Wij vermeenen bovendien, dat, waar men staat tussehen zijn eigen land en den vreemde, ongetwijfeld aan het eerste de voorkeur behoort te worden gegeven. Dit is een plicht niet alleen van vaderlandsliefde, maar ook ran welbegrepen eigenbelang.

In tegenstelling van den geachten schrijver der "Finantiële Beschouwingen bij den aanvang van het jaar 1868 , bl. 5 , gelooven wij, "dat de Amerikaansche waarden in het geheel niet naar "menschelijke berekening tegen de gevolgen eener finantiële "krisis zullen vrijwaren." Onzes inziens zal hij in de vijf jaren, die verloopen zijn sints het oogenblik waarop hij zijue beschou- 
wingen ter juder schreef, wel eenigzints van gevoelen veranderd zijn en tot eene meer pessimistische beschouwing zijn geleid. Het zal wellicht nog lang moeten duren eer aan het groote publiek de oogen geheel opengaan. Misschien zullen er nog meer slachtoffers moeten worden getnaakt, vóór en aleer de publieke opinie over de Amerikaansche spoorwegwaarden onberroepelijk het anathema heeft uitgesproken. Alle die waarden over ééne en dezelfde kam te scheren zou eene grove onbillijkbeid zijn; want er zijn er inderdaad onder, welke nimmer in hare verplichtingen zijn to kort geschoten. Bij gebreke echter van de noodige gegevens en bescheiden ralt het zoo moeijelijk de goede van de kwade te onderscheiden on gaan wij dus af op hetgeen wij tegenwoordig zien gebeuren, maken daaruit onze redeneringen en trekken onze conclusiën, die natuurlijk alles behalve gunstig kunnen zijn. Het is daarom, dat eene bekwame, onafhankelijke en vooral eerlijke finantiële pers, die hare roeping begrijpt, zoo onberekenbaar veel goeds kan stichten door het voorlichten van het groote publiek in alles, waarover haar oordeel wordt ingeroepen en hare medewerking en steun gevraagd.

$W_{1 j}$ eindigen, echter niet zonder nogmaals een beroep te hebben gedaan op allen, die het wel meenen met het Moederland en zijne koloniën, om onzen inlandschen handel en nijverbeid niet uit het oog te verliezen. Laat de vorstelijke stem, die zich nog kort geledern in Neêrlands hoofdstad liet hooren, om de onverschilligen op te wekken en de slapenden wakker te schudden, geene stem des roependen in de woestijn zijn geweest, maar laat ons toonen dat wij de energieke pogingen weten te waarderen van den vorst, die ons voorgaat met het verstrekken van zijnen morelen en materiëlen steun aan alles, wat de nationale welvaart kan verhoogen en die zich daartoe gaarne de aanzienlijkste geldelijke opofferingen getroost. Terwijl eene inschrijving op eene Amerikaansche spoorweg-onderneming niet de minste tegenkanting ontmoet, ja altijd het bedrag der leening verre overtreft, is voor een echt nationale zaak nog steeds moeielijk kapitaal te vinden. De Indische Droogdok-Maatschappij heeft dit nog weinige maanden geleden moeten ondervinden, en zou ongetwijfeld niet tot stand zijn gekomen, wanneer niet de president van het voorloopig comité aan de vergadering voorgesteld had, het resterend bedrag der leening onder elkander te verdeelen.

Amerika is ontegenzeggelijk een land, dat door zijne snelle en krachtige ontwikkeling geheel Europa heeft in verbazing gebracht, 
en dat wegens de onmetolijkheid zijner lunlpbronnen, nog steeds aan velen eene schoone toekomst opent. Tallooze en reusachtige werken van openbas nut zijn door de energie van zijne bewoners tot stand gekomen en werpen thans groote en schoone voordeelen op. Maar het behoeft nog steeds reel kapitaal, en onder alle die schoone voorstellingen, die steeds met de lichtste en helderste kleuren worden geschilderd en afgemaald, schuilt naar onze ernstige overtuiging veel, wat den toets der waarheid niet altijd even streng kan doorstaan en niet altijd aan de eerste eischen eener gezonde critiek kan beantwoorden. Behoedzaaunheid zij voortaan eene onzer eerste plichten en doe ons niet vergeten, dat betgeen uit de Nieuwe Wereld tot ons overkomt, in bet gebeel niet altijd boven verdenking verheven is.

Amslerdam.

Mr. J. v. A. 


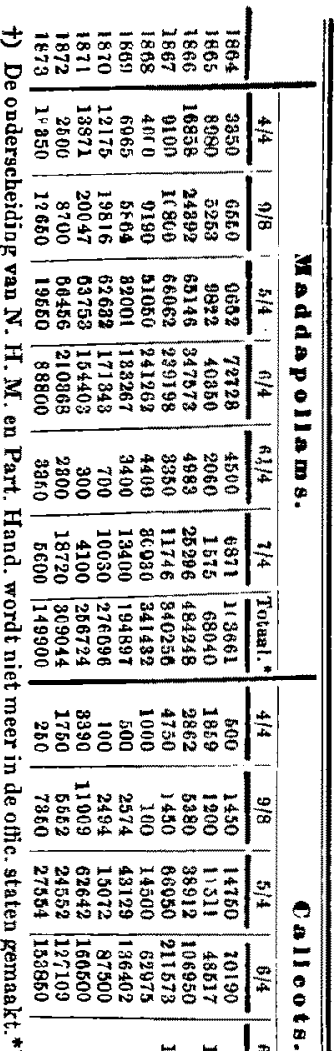

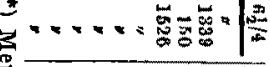

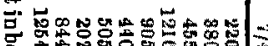

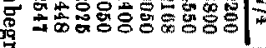

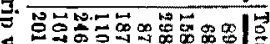

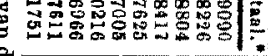

策

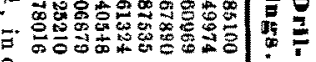

政

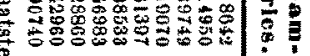

等

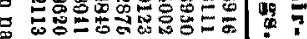

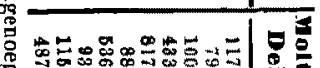

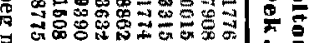

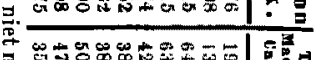

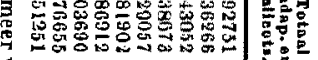

管

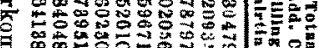

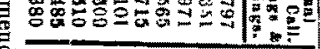

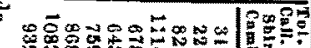

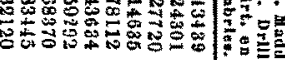

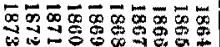

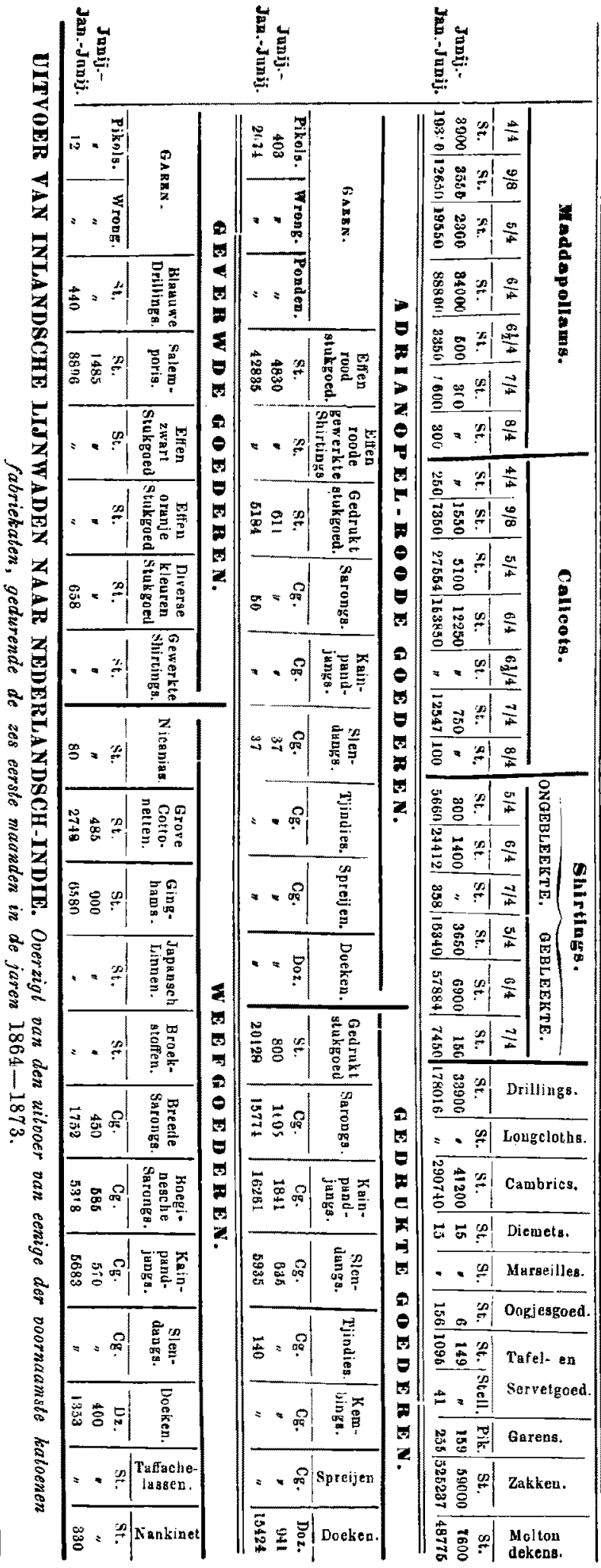

:

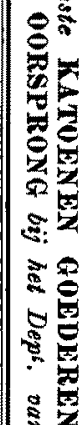

4

용

돈

:

으:"

*

5.

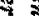

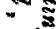

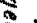

8

है

을

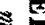

急

要

a) 5

2 ह ․․․

$-1$

는 풀

是 .

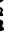

